\title{
Reducing plagiarism through academic misconduct education
}

\author{
Mike Perkins $^{1 *} \mathbb{D}$, Ulas Basar Gezgin ${ }^{2}$ and Jasper Roe ${ }^{1}$
}

\author{
*Correspondence: mgperkins@ \\ gmail.com \\ ${ }^{1}$ British University Vietnam, BUV \\ Ecopark Campus, Ecopark Township, \\ Hung Yen, Vietnam \\ Full list of author information is \\ available at the end of the article
}

\begin{abstract}
Although there is much discussion exploring the potential causes of plagiarism, there is limited research available which provides evidence as to the academic interventions which may help reduce this. This paper discusses a bespoke English for Academic Purposes (EAP) programme introduced at the university level, aimed at improving the academic writing standards of students, reducing plagiarism, and detecting cases of contract cheating. Results from 12 semesters of academic misconduct data $(n=12,937)$ demonstrate a $37.01 \%$ reduction in instances of detected plagiarism following the intervention, but due to limited data, cannot demonstrate a direct impact on reducing detected rates of contract cheating. The results also show a lower than expected proportion of plagiarised assignments (3.46\%) among submissions.
\end{abstract}

Keywords: Academic misconduct, Plagiarism, Contract cheating, Turnitin, Academic dishonesty, Ghost-writing, EAP intervention, fingerprinting

\section{Introduction}

Academic dishonesty is not a new problem for higher education service providers. However, the rising availability of information sources which can easily be accessed by student writers, as well as essay-writing services heavily marketed towards university students, has led to an increase in discussions on this topic in both the media and academic journals. One way in which universities have attempted to monitor and control academic integrity is through the use of text matching software such as Turnitin. However, Turnitin and other software packages used to detect similarities between text submissions have been widely acknowledged as far from a perfect solution to 'solve' plagiarism (Heckler et al. 2012; McKeever 2006; Scheg 2012) as they do not inherently detect whether plagiarism has occurred.

Aside from cases of plagiarism that can be detected using text matching software, other, more subtle and difficult to detect forms of plagiarism such as contract cheating also need to be addressed. Throughout this paper, we use the term 'contract cheating' to refer to any form of plagiarism where a student has contracted another individual or organisation to carry out assessed work on their behalf.

(c) The Author(s). 2020 Open Access This article is licensed under a Creative Commons Attribution 4.0 International License, which permits use, sharing, adaptation, distribution and reproduction in any medium or format, as long as you give appropriate credit to the original author(s) and the source, provide a link to the Creative Commons licence, and indicate if changes were made. The images or other third party material in this article are included in the article's Creative Commons licence, unless indicated otherwise in a credit line to the material. If material is not included in the article's Creative Commons licence and your intended use is not permitted by statutory regulation or exceeds the permitted use, you will need to obtain permission directly from the copyright holder. To view a copy of this licence, visit http://creativecommons.org/licenses/by/4.0/. The Creative Commons Public Domain Dedication waiver (http://creativecommons.org/publicdomain/zero/1.0/) applies to the data made available in this article, unless otherwise stated in a credit line to the data. 
Although student use of contract cheating services are not new (Lancaster and Culwin 2007) and prevalence of this behaviour is low (Rundle et al. 2019), they are becoming more visible, to the point where it is not uncommon to see these services advertised on social media. These services show evidence of being mature, wellestablished commercial operations, suggesting that there is a substantial demand feeding this supply (Ellis et al. 2018).

In this study, we present and discuss an intervention designed to improve the academic writing skills of students, reduce levels of plagiarism, and provide a tool to assist in the detection of contract cheating, by capturing a 'fingerprint' of a writing sample in an offshore international higher education service provider: British University Vietnam (BUV). BUV has operated in Vietnam's capital city, Hanoi, since 2009. Although the faculty are entirely expatriate employees, almost all the students are Vietnamese, and therefore use English as their second or even third language. BUV faces the same problems as any other university with regards to plagiarism threats. However, due to the suggested negative relationship in the literature between English language ability and the propensity to commit plagiarism (Abasi and Graves 2008; Bretag 2007; Chen and Ku 2007; Goh 2015; Jones 2011; Li 2015; Marshall \& Garry 2006; Perkins et al. 2018; Pennycook 1996; and Walker and White 2014), BUV must be more aware of the potential threats of plagiarism in its student body. In this paper we focus specifically on how the use of a bespoke English for Academic Purposes (EAP) programme (referred to internally as the Academic English Masterclass) may improve the academic writing skills of students, assist in reducing overall plagiarism levels within BUV, and specifically, assist in the identification of cases of contract cheating. As proposed by Kakkonen and Mozgovoy et al. (2010), we demonstrate how a final exam for this programme may be used to help identify potential cases of contract cheating by providing 'fingerprints' of a writing style which may be checked for consistency against a piece of work submitted later.

\section{Literature review}

Although there are multiple definitions and characterisations of plagiarism (see: Park 2004; Bennett et al. 2011; Mozgovoy et al. 2010), for the purpose of this paper, we refer to plagiarism as an act of submitting a document that belongs partially or completely to somebody else without due reference, and therefore misrepresents the effort that has been carried out by the submitting author. It is important to recognise that plagiarism can also occur unintentionally. We believe that the primary benefit of the initiative we present is that it has the potential to reduce instances of unintentional plagiarism by developing the academic skills of students, whilst also serving as a disincentive to the minority of students who seek to benefit by engaging in one or more deliberate forms of plagiarism discussed above. However, as the analysis presented in this paper uses institutional data on detected cases of plagiarism, we cannot differentiate between deliberate and accidental cases of plagiarism.

The reasons students engage in plagiarism has been well explored in numerous other papers, but as most students at BUV are Non-Native English Speakers (NNES), we wish to highlight the effect that low levels of English may have on incidences of plagiarism. This finding is supported by Bretag et al. (2018) who found that a factor influencing 
contract cheating prevalence was the use of a language other than English in students' homes. Studies which have found a generally negative relationship between English language ability and plagiarism include Abasi and Graves (2008), Bretag (2007), Bretag et al. (2018), Chen and Ku (2007), Goh (2015), Jones (2011), Li (2015), Marshall and Garry (2006), Pennycook (1996), Perkins et al. (2018), and Walker and White (2014). However, many studies exploring this relationship are based on self-reported data from both students (Goh 2015; Jones 2011) and faculty (Abasi and Graves 2008; Bretag 2007; Li 2015; Walker and White 2014) which raise methodological concerns about the potential validity of this relationship.

In terms of interventions which may assist in combatting plagiarism, several options have been suggested in the relevant literature. These include an online academic integrity module (Belter and du Pré 2009; Curtis et al. 2013), a web-based module with a blended method on plagiarism (Stetter 2013), an online quiz through Blackboard (O'Donnell 2011), a plagiarism assignment (Davis 2011), an ethics-related module (Guo 2011), computer simulations and games as a preventative measure (Bradley 2015), marker training and the use of novel detection software, (Dawson et al. 2019; Dawson et al. 2019) and student plagiarism workshops (Chen and Van Ullen 2011; Hoanca 2019). Soto et al. (2004), and Levine and Pazdernik (2018) provide clear evidence of a reduction in plagiarism following a combination of initiatives, including structured educational modules, implementation of policies, increasing the difficulty of plagiarism by requiring students to submit drafts, and ensuring there are consequences of plagiarism. The fear of consequences arising from being caught committing plagiarism was also shown to be a strong deterrent to plagiarism by Bennett (2005). Amigud and Lancaster (2019) also identify that in some cases, familial involvement occurs in the process of purchasing contract cheating services, although it is not specified how this takes place. The authors suggest that ultimately, reducing contract cheating should focus on detection rather than attempting to stop it happening in the first place.

Proposals which have been suggested to specifically reduce contract cheating include: collecting writing samples from students (McLafferty and Foust 2004; Jones \& Sheridan, 2014); setting assignments that specifically refer to lecture contents rather than generic essays (McLafferty and Foust 2004); improving the teaching and learning environment, including the relationship between staff and students and reducing the turnaround time of assessments (Wallace and Newton 2014); 'designing out' plagiarism (Fazel and Kowkabi 2014) by providing alternative forms of assessment such as exams, oral presentation (Lines 2016), internship experience and field trip-based reports, as part of a holistic assessment methodology (Goh 2015); and incorporating assessments that involve critical thinking and personal involvement with the course content (Carroll 2007; Heckler et al. 2012; McLafferty and Foust 2004; Probett 2011).

There is limited research in the field providing evidence of how contract cheating may be detected in the first place. Clarke and Lancaster (2007) present a 'Six-Stage Contract Cheating Detection Process' for identifying incidences of contract cheating in computer science assignments. However, this method relies on the availability of public information; in this case, 'bids' to an auction site. This ignores a common pathway of students obtaining papers from 'essay mills' or from advertisements on private social media groups. Morris (2018) on the other hand, suggests a more holistic model of five considerations for addressing contract cheating, including determining strategy, 
reviewing institutional policy, developing an understanding of students, edited and revisiting practices for assessment and including areas for staff professional development.

Koppel and Winter (2014) demonstrate how computational linguistic methods can be used to determine whether the author of two documents is the same. Although the results of their study indicate that this method has a good degree of accuracy in determining whether two documents were written by one author, it relies on having access to digital copies of all text being examined. This method is therefore unable to determine whether contract cheating has taken place, as it is not possible to analyse work from authors who are not in the existing database.

Clare et al. (2017) present a method of determining whether contract cheating may have occurred by examining whether unusual patterns exist between the grades received by students for unsupervised work compared to those for supervised work. This approach may be helpful to identify where further investigation could take place, but given the wide range of factors which could also influence differences in grades between different types of assessment (student preferences, differences in grading practices between markers, quantitative vs qualitative assessments, etc.), it cannot be relied upon by itself as a tool to identify contract cheating.

Dawson and Sutherland-Smith (2018) show that experienced markers were able to detect contract cheating $62 \%$ of the time in one experiment. However, these papers were all obtained from dedicated contract cheating websites which may be of varying quality, and the study only examined twenty papers from one course.

Harper et al. (2020) demonstrate that staff are generally skilled at detecting contract cheating rates for text-rich assessments, but this reported detection rate was lower for exam-based assessments as opposed to take-home assignments.

Although it is very easy for software solutions to identify text that is already present in its database, the ability of current software is not yet advanced enough to detect the complexities of contract cheating (Kakkonen and Mozgovoy 2010; Mozgovoy et al. 2010). As advances in technologies such as deep learning, neural networks, and quantum computing develop and become available for use in higher education, these difficulties may be eased. It is worth noting that new products from Turnitin such as Authorship Investigate have shown potential in identifying contract cheating cases (Dawson et al. 2019) although are not yet widely available. As software cannot adequately assist with detecting incidences of contract cheating, this is therefore left to faculty. However, studies such as Lines (2016) and Malesky et al. (2016) have shown how these contract cheating services can both be undetected by faculty (despite knowledge of their use) whilst also providing acceptable grades for the students engaging in these practices.

As there have been few reports of studies which have been specifically designed to both reduce plagiarism and identify potential cases of contract cheating, we contribute to the literature by detailing the methods which BUV have taken in order to resolve this problem, whilst at the same time increasing the academic writing capabilities of our students.

\section{Language, plagiarism and context in British University Vietnam (BUV)}

BUV is a private educational institution which began operations in 2009. BUV holds a unique position in Vietnam's higher education system, as the only university to offer 
entirely British undergraduate programmes which are accredited by and offered in partnership with two UK universities. As of February 2020, BUV has approximately 700 students primarily studying degrees in Business and Management subjects.

The majority of BUV students are NNES and study a programme comprising two semesters of study per academic year. All students who begin a course of study must have achieved an English language proficiency score: either an official IELTS Band score of 6.0 with no sub-skill below 5.5, or an alternative English language qualification equivalent to this level.

BUV is in the process of undertaking rapid expansion and has recently relocated to a suburban campus with a capacity for over 7000 students. This dramatic increase in scale has the potential to give rise to new and increased risks for academic quality and reputation, and so it is imperative that appropriate measures are employed to safeguard the quality and rigour of the programmes offered during this period of growth and in the future. Consequently, the faculty of BUV has been working towards the development of an intervention to detect, reduce, and deter students from voluntarily or involuntarily participating in behaviours which would constitute plagiarism, whilst at the same time improving the key language and study skills required by students studying in an international educational setting.

Prior to the introduction of the BUV intervention in April 2016, faculty had identified that many students in their classes may benefit from additional support in developing their academic study skills. BUV had, by chance, also discovered some challenging cases of contract cheating and were also anecdotally aware that this was more common in the student body than previously thought. Due to the historical reliance in the institution on Turnitin as the key tool to identify instances of plagiarism, a new approach to managing the academic integrity of the university needed to be taken which could further improve the English language ability of students.

As any potential threats to the academic integrity of the BUV programmes need to be taken extremely seriously, and the potential benefits to the English language ability of students were clear, the introduction of an initiative to tackle both issues was required. The highly competitive market of private, international higher education in Vietnam also means that any additional benefits provided to students may act as market differentiators. By developing an initiative which could tackle both issues at BUV, and therefore increase the likelihood of students attaining good degrees, this would likely act as a potential selling point to the fee payers and decision makers (most often the parents of students). In this market, as in many others, a strong reputation is a key decision-making factor in the choice of universities. If there was a suggestion that the academic integrity of BUV was anything other than impeccable, this could cause significant problems with student recruitment, as well as damage our relationships with local and international stakeholders.

This intervention had to address several key concerns. Firstly, students had to be provided with additional academic English classes in order to attempt to reduce feelings of low confidence and improve their overall ability to write in English. Secondly, students also had to receive additional support in terms of time management and fostering motivation. An intervention had to provide a tangible, stringent method of detecting instances of contract cheating. Finally, the intervention had to specify the rules and codes of conduct relating to academic integrity expected in an international university 
environment, while being careful not to fall into the trap of assuming that Western academic values are a universal constant.

\section{The intervention: Academic English Masterclass}

Based upon the analysis presented above, BUV approved the creation of a standalone compulsory module for all undergraduate students, entitled Academic English Masterclass (AEM) which ran for the first time in April 2016.

The module consists of 2 hrs of class-based tuition per week for 12 weeks for all undergraduate students and culminates in a novel final exam, which functions as both a control and benchmark for students' English writing ability as well as enabling fingerprinting of submitted work to be carried out.

The process of syllabus development was based on a needs analysis, as suggested by Nunan (1988), of a convenience sample of 30 students, targeting their 'necessities, lacks, and wants' (Nation and Macalister 2010, p.25) and adapted for the East Asian context based on the research of Cai (2013). This was combined with informal one-to-one interviews with all 30 members of the sample group, and an initial diagnostic test in the form of a written essay. The needs analysis revealed that in terms of composition skills, students required the most assistance with essay planning, paraphrasing, referencing, and finding relevant sources of information. Many final year students admitted to plagiarising when they were unable to put ideas into their own words or were unable to identify the boundaries of utilising others' material versus academic misconduct. This suggests that although first year students may require more focussed training on academic misconduct policy and basic EAP training, the requirements for final year students may be different. This insight was incorporated into the design of the course.

A final consideration in the design of the programme was the international context of BUV. Academic integrity is far from a universal concept and ignores the Eastern academic tradition of duplicating material as homage (Stowers and Hummel 2011). This is an important consideration in terms of understanding students' interpretation of plagiarism, and it is possible that the view of reusing material in 'homage' is not seen by all students in this cultural context as a breach of academic integrity. However, research on this area is conflicted, and some authors suggest that plagiarism is more frequently linked to individual preference rather than cultural acceptability (Martin 2011). Regardless of this potential cultural paradigm clash, it remains important in this context that the AEM programme explicitly teaches and explains the underlying philosophical foundations of the British academic system, and the conventions that must be followed to avoid committing plagiarism.

The needs analysis led to the development of a multidimensional syllabus with the course goal of raising the awareness of acceptable practices surrounding plagiarism and academic misconduct, whilst at the same time, developing students' researching and writing skills. This is tested by a final written assessment under exam conditions. Students are provided with a set of multiple-choice questions to assess knowledge about acceptable academic practices, and are also set a writing task. In this task they are given extended extracts from a variety of sources, including academic and non-academic 
sources of information with differing degrees of bias, and must tackle an essay question in which they utilise these sources. This procedure ensures that the essay written by the student (and subsequently used as a fingerprint) is entirely their own work, ${ }^{1}$ and also provides them with the opportunity to demonstrate their ability in every facet of academic writing, including not only grammatical and lexical accuracy, but also the skills of paragraphing, paraphrasing, referencing, and critical thinking (as text extracts must be analysed for their impartiality). Alongside the original exam script is a companion piece, written by the marker, that contains several key points related to the writer's ability, along with a band score of 1-9, which is developed based on a rubric and band score system of English proficiency. The rubric and band system scores students on grammatical accuracy, coherence, academic skills (referencing, paragraphing, and synthesis of material), and vocabulary. The marked sample is available for checking by faculty by the time students submit their summative assignments for their academic modules.

Markers must carry out a check using the writing sample on all high scoring assessments (papers scoring $70 \%$ and above), as well as a random selection of $10 \%$ of papers from each set of assessments, with a minimum sample size of six papers. Although all grading is carried out anonymously, once a paper has been graded, markers are permitted to use the student number to match up with the student name to aid in initial authorship investigation. All markers are trained how to perform these checks, and this process is discussed later in the paper.

Following the introduction of this intervention, all students were reminded of the dangers of plagiarism and new warnings were introduced to all assignment guidelines highlighting the severity of consequences if students were caught plagiarising. All students were made aware that their writing samples obtained during the AEM exam would be made available online for faculty and misconduct panels to check if there were any suspicions regarding their writing. New writing samples are obtained every semester from students, approximately 3 weeks before the assignment submission period begins in order to reduce the likelihood of significant changes being seen in the writing styles of students over time.

\section{Methods and analysis of results}

Data collection and screening

If any student submission is flagged by a marker as a potential plagiarism or contract cheating case, a process is initiated by the faculty members which ends in the student being notified by the administration that that they are required to attend an informal meeting to discuss their work. Most cases of plagiarism are resolved at this stage and any penalties recorded. If, after this stage, there are concerns regarding potential contract cheating students are requested to attend an academic misconduct panel and participate in a viva voce of their submission in the presence of both a subject matter

${ }^{1}$ Bretag et al. (2018) demonstrate the widespread nature of cheating in university exams and Harper, Bretag and Rundle (2020) demonstrate the lack of ability of markers to detect this, which raises a question regarding this statement. However, given the relatively low stakes of this particular assessment, and that it is the writing style of the student that we are most interested in as opposed to the content, we believe this to not be of major concern. 
expert and a misconduct expert. Following the viva, if this panel has remaining suspicions of contract cheating, then the case is escalated to the most serious university panel for a meeting with the student. This panel will make the final decision as to whether contract cheating has occurred and will use a wide variety of sources of evidence in making its final decision. These include the writing samples obtained during the AEM exam, statements from relevant faculty, the previous marks obtained by the student, results from the initial viva and additional questions which the panel may put to the student. As the typical penalty for a student found to have utilised any contract cheating services is a failure of their award, it is the responsibility of the university to establish proof beyond reasonable doubt in these cases, and no decision is made solely on the basis of the comparison of the fingerprint with the submitted piece of work. The procedures used by BUV are set by the awarding body, and there is an appeal process available to the student.

In February 2020, we conducted an analysis of the plagiarism and contract cheating cases recorded during this process from the semesters of April 2014 through October 2019 to answer three questions:

1. What is the overall prevalence of plagiarism committed by students at BUV?

2. Has the AEM initiative been successful in reducing plagiarism cases?

3. Has the AEM initiative been successful in reducing detected incidences of contract cheating?

Before carrying out the analysis, the data was screened in the following way: Firstly, all recorded cases where a misconduct panel determined that no form of plagiarism had occurred in the flagged submission, and therefore gave a verdict of 'no case to answer', were removed. Any incidences where a verdict of 'poor academic practice' was given by the panel solely due to poor referencing practices were also excluded from the results. If one student had been punished for several plagiarism violations, each incident was counted separately.

The results of this analysis are shown in Table 1.

\section{Overall prevalence of plagiarism and contract cheating}

From a total of 12,937 student submissions, analysis of the data revealed 448 plagiarism offences over the twelve-semesters between April 2014 and October 2019. The percentage of submissions found to have contained some element of plagiarism (excluding contract cheating cases) ranged between $2.35 \%$ and $7.08 \%$ each semester, with a mean percentage of $3.46 \%$ across the period of study. As the dataset covers multiple years, some incidences of plagiarism were from individual students who had committed plagiarism offences over multiple semesters.

With the caveat that it is possible that the study may underestimate plagiarism in the student body (as it would be unwise to believe that any higher education institution detects $100 \%$ of plagiarism cases), the first point to note is that the prevalence of detected plagiarised submissions is much lower than described in previous studies examining plagiarism data (as opposed to self-report studies). These studies have revealed mean rates of plagiarism of 26\% $(n=182)$ (Barret \& Malcolm 2006), 26.2\% $(n=290)$ (Walker 2010), and $10.8 \%(n=74)$ (Warn 2007) respectively. Within a specifically Vietnamese 
Table 1 Descriptive Plagiarism Results at BUV

\begin{tabular}{|c|c|c|c|c|c|c|c|}
\hline & $\begin{array}{l}\text { Semester } \\
\text { start date }\end{array}$ & $\begin{array}{l}\text { Number of } \\
\text { assignment } \\
\text { submissions }\end{array}$ & $\begin{array}{l}\text { Number } \\
\text { of } \\
\text { detected } \\
\text { cases of } \\
\text { plagiarism }\end{array}$ & $\begin{array}{l}\text { Plagiarism } \\
\text { cases as } \\
\text { percentage } \\
\text { of } \\
\text { assignment } \\
\text { submission }\end{array}$ & $\begin{array}{l}\text { Number } \\
\text { of } \\
\text { detected } \\
\text { Contract } \\
\text { Cheating } \\
\text { cases }\end{array}$ & $\begin{array}{l}\text { Contract } \\
\text { Cheating } \\
\text { cases as } \\
\text { percentage } \\
\text { of plagiarism } \\
\text { cases }\end{array}$ & $\begin{array}{l}\text { Contract } \\
\text { Cheating cases } \\
\text { as percentage } \\
\text { of assignment } \\
\text { submissions }\end{array}$ \\
\hline \multirow{4}{*}{$\begin{array}{l}\text { Results prior } \\
\text { to the } \\
\text { introduction } \\
\text { of the AEM } \\
\text { intervention }\end{array}$} & $\begin{array}{l}\text { April } \\
2014\end{array}$ & 642 & 33 & $5.14 \%$ & 1 & $3.03 \%$ & $0.16 \%$ \\
\hline & $\begin{array}{l}\text { October } \\
2014\end{array}$ & 715 & 21 & $2.94 \%$ & 1 & $4.76 \%$ & $0.14 \%$ \\
\hline & $\begin{array}{l}\text { April } \\
2015\end{array}$ & 933 & 37 & $3.97 \%$ & 1 & $2.70 \%$ & $0.11 \%$ \\
\hline & $\begin{array}{l}\text { October } \\
2015\end{array}$ & 847 & 60 & $7.08 \%$ & 8 & $13.33 \%$ & $0.94 \%$ \\
\hline \multirow{8}{*}{$\begin{array}{l}\text { Results } \\
\text { following the } \\
\text { introduction } \\
\text { of the AEM } \\
\text { intervention }\end{array}$} & $\begin{array}{l}\text { April } \\
2016\end{array}$ & 872 & 31 & $3.56 \%$ & 3 & $9.69 \%$ & $0.34 \%$ \\
\hline & $\begin{array}{l}\text { October } \\
2016\end{array}$ & 799 & 55 & $6.88 \%$ & 0 & $0.00 \%$ & $0.00 \%$ \\
\hline & $\begin{array}{l}\text { April } \\
2017\end{array}$ & 994 & 39 & $3.92 \%$ & 1 & $2.56 \%$ & $0.10 \%$ \\
\hline & $\begin{array}{l}\text { October } \\
2017\end{array}$ & 1064 & 43 & $4.04 \%$ & 0 & $0.00 \%$ & $0.00 \%$ \\
\hline & $\begin{array}{l}\text { April } \\
2018\end{array}$ & 940 & 31 & $3.30 \%$ & 1 & $3.23 \%$ & $0.10 \%$ \\
\hline & $\begin{array}{l}\text { October } \\
2018\end{array}$ & 1492 & 9 & $0.60 \%$ & 1 & $11.11 \%$ & $0.07 \%$ \\
\hline & $\begin{array}{l}\text { April } \\
2019\end{array}$ & 1577 & 37 & $2.35 \%$ & 2 & $5.41 \%$ & $0.13 \%$ \\
\hline & $\begin{array}{l}\text { October } \\
2019\end{array}$ & 2062 & 52 & $2.52 \%$ & 0 & $0.00 \%$ & $0.00 \%$ \\
\hline \multicolumn{2}{|c|}{$\begin{array}{l}\text { Total/Average before } \\
\text { AEM: }\end{array}$} & 3137 & 151 & $4.81 \%$ & 11 & $7.28 \%$ & $0.35 \%$ \\
\hline \multicolumn{2}{|c|}{$\begin{array}{l}\text { Total/Average after } \\
\text { AEM }\end{array}$} & 9800 & 297 & $3.03 \%$ & 8 & $2.69 \%$ & $0.08 \%$ \\
\hline \multicolumn{2}{|c|}{ Total/Average overall: } & 12,937 & 448 & $3.46 \%$ & 19 & $4.24 \%$ & $0.15 \%$ \\
\hline
\end{tabular}

context, Ba et al. (2016) found that $73 \%(n=681)$ of the submissions tested in their study had Turnitin similarity indexes of over $20 \%$, and Tran et al. (2017) found that in their studies of two Vietnamese universities, there were plagiarism levels (defined by similarity indexes over $24 \%$ ) of $91.7 \%$ and $61.7 \%{ }^{2}$ Our study differs from those cited above due to the longitudinal aspects of the data collection period, meaning that a much larger sample has been obtained for analysis.

The results may indicate that BUV students demonstrate a lower predilection towards plagiarism than the norm, however, they are more likely explained by the large sample utilised in the study. Even though faculty (Andrews et al. 2007) and students (Scanlon and Neumann 2002) alike may consider plagiarism to be a significant problem

\footnotetext{
${ }^{2}$ The authors of these papers suggest that this equates to a high probability of plagiarism having occurred, however text matching software such as Turnitin does not identify plagiarism, it simply identifies similarities in documents which may indicate that plagiarism has occurred in some form. Just because there is a high degree of similarity identified, does not necessarily mean that an author has engaged in plagiarism. This may occur in cases where students have submitted improved versions of papers as part of a continuous assessment initiative.
} 
in their institutions, our results demonstrate that a quantitative analysis of a larger data sample could reveal a lesser problem than initially imagined. Despite the professed increased propensity of non-native English speaking 'International' students to commit plagiarism (Walker 2010), the low levels of plagiarism indicated in the set of submissions (even though almost all submitting students are NNES) indicates that this suggestion is not universally accurate, a viewpoint echoed by Soto et al. (2004).

Identified levels of contract cheating were overall very low, with a total number of 19 cases over the period, ranging from $0 \%$ to $0.94 \%$ of submissions per semester, with a mean percentage of $0.15 \%$ of the total number of submissions in the time period. This prevalence rate is significantly lower than the figures reported by Curtis and Clare et al. (2017), of 3.5\% of students (not submissions) having committed these offences, and by Harper et al. (2020) of 2.6\%. However, as contract cheating cases are more difficult to detect than more 'traditional' plagiarism offences (whether intentional or unintentional), we recognise that the detected cases are unlikely to be fully representative of the actual levels of contract cheating in the student body.

\section{Effectiveness of the AEM in reducing plagiarism}

Prior to the introduction of the AEM intervention in the April 2016 semester, the mean percentage of submissions found to contain plagiarism was $4.81 \%(n=3137)$ Following the introduction of the intervention, the mean percentage of submissions found to contain plagiarism dropped to $3.03 \%(n=9800)$; a $37.01 \%$ decrease from the results prior to the intervention. Although the rates of plagiarism were already low prior to the introduction of the AEM, the further reduction in plagiarism demonstrates that the intervention has achieved one of its stated aims of educating students about appropriate academic standards and reducing levels of plagiarism. These findings are in line with those of Soto et al. (2004), and Levine and Pazdernik (2018), demonstrating that training programmes such as the AEM may help reduce plagiarism.

\section{Effectiveness of the AEM in reducing contract cheating}

With regards to the prevalence of contract cheating before and after the AEM intervention, the results do show a reduction in the percentage of contract cheating cases detected, from $0.35 \%$ of submissions, to $0.08 \%$ of submissions, a $77.14 \%$ decrease. With the assumption that the decrease in identified cases is not due to any decrease in the ability of markers to detect these (given the additional training that occurred), this apparent reduction in contract cheating may be due to several factors or a combination of these factors. Firstly, an improvement in student knowledge of appropriate academic standards may have increased the awareness of what is expected of them in a university setting. Secondly, knowing that there will be increased scrutiny of their submissions regarding contract cheating, and the knowledge that samples of their work are available for checking may have increased the perceived risk of contract cheating. Thirdly, any reduction may be due to real improvements in the EAP abilities of the students. As the English language ability of students has been shown to be linked to plagiarism, the increased EAP skills of the students may have reduced the perceived need to obtain contract cheating services. 
However, the relative rarity of contract cheating as a percentage of submissions, and the very small total number of cases over the entire period of investigation do not allow us to make any firm conclusions as to the effectiveness of this intervention on the reduction of detected cases of contract cheating. The relatively large number of cases identified in the October 2015 semester compared to other semesters, and the limited periods of data collection prior to the introduction of the intervention have likely made a comparison of contract cheating data before and after the intervention untenable.

Despite this, we believe that continuing with this initiative is important. By continuing to educate students in academic writing skills and expected academic practice, as well as establishing a protocol of collecting and checking student writing samples, we can reduce plagiarism, provide a disincentive for students who may seek to engage in contract cheating, and obtain a valuable data source for the further investigation of any such detected cases.

\section{Discussion}

Although the preliminary results of this intervention are promising, any benefits of an intervention such as the AEM must be considered alongside an understanding of the numerous challenges of any intervention involving the collection and comparison of student writing samples.

Firstly, faculty carrying out marking of assessments must know which submissions are suspicious, and therefore warrant checking against the student fingerprints. In order to do this on an ad-hoc basis, some prior expectations as to the quality of the submitted work must be held. Although some faculty may be aware of the general quality of work they are expecting from a set of assignment submissions, the use of anonymous marking means that as long as the quality of work is generally in line with the entire cohort, markers may not necessarily detect a clear difference between contracted and legitimate assignments. As the size of student cohorts increases, this leads to a wider spread of both marks and writing styles being expected, and the likelihood of faculty having initial suspicions is further reduced, therefore compounding this problem. For institutions which have a high concentration of NNES, an additional challenge which may be encountered is that of fellow NNES students being hired for contract cheating, as opposed to 'professional' native English speaking contract cheating services. This sub-type of contract cheating may be more appealing to some students, as fellow NNES students may have similar writing styles and have completed the same, or similar classes. This means that the differences between these submissions and fingerprinted work may not be as apparent when compared to the results obtained from professional contract cheating websites.

Secondly, faculty may not always accurately detect cases of contract cheatings, even if a submission is checked for consistency against the fingerprinted sample. Markers will likely have differing skill levels in their ability to accurately detect differences in writing styles between a submission and a fingerprint and some cases may be missed. Therefore, any institution considering the introduction of fingerprinting must be aware of the potential increase in false negatives occurring due to some submissions not being investigated appropriately and implement training programmes to address this. This method also does not address cases where a writing sample would not be helpful in determining authorship of an assessment, such as computer coding or artwork. 
Conversely, the potential risk of false positives must also be considered. If faculty members flag a submission as a possible case of contract cheating due to a change in writing styles between a fingerprint and a submitted assignment, there must be a fair and consistent approach to investigating these cases fully. Markers must also be aware that improvements in English language abilities and writing styles are likely to be seen when comparing what can be produced under timed, exam conditions, compared to a take-home assignment, as students will have had time to proofread, plan, edit, and check their final submission.

Research by Dawson et al. (2019) has indicated that the training of markers can improve their ability to identify contract cheating, therefore to minimise the problems stated above, all faculty members receive training on how to assess work for potential cases of contract cheating, and assessments are only graded by faculty who have completed this training. When checking for potential evidence of contract cheating, markers are asked to investigate several things. The initial step is an overall comparison of the student's writing in the unsupervised, external assessment with the sample produced under exam conditions. If a student produced a flawless submission in adherence to all academic standards, but during the AEM written exam had received a low score in this area, or the overall standards of English were very different, this might indicate a second or alternate author.

Other techniques based on forensic linguistics are also used. These include comparing the submission with the sample to see if there are mismatches between the writer's unique choice of words and individual style of writing (idiolect), and their tendency to use certain constructions (coselection and lexical choice) (Coulthard, 2010).

Markers are also trained to identify other potential indicators of contract cheating, either of the whole document, or of partial sections. These indicators include changes in formatting or styles of writing in different sections of the text, as well as examining the document properties for any suspicious elements such as very short editing times (indicative of content being copied into a brand new document before submission), or whether there are inconsistences in the named author of the document. Even the choice of sources used or not used in a submission could raise suspicions: for example, not citing key sources indicated during class sessions. By training all markers how to check for contract cheating, making comparisons between the sample and submissions part of the marking procedure, and carrying this procedure out on a regular basis, it is our hope that we can improve the capacity of markers to identify instances of contract cheating.

Although individually none of the above indicators would ever be considered conclusive evidence of contract cheating, and the fingerprinting method has significant limitations as discussed, all the above can be employed by a panel investigating whether academic misconduct may have occurred.

Reducing and detecting plagiarism and contract cheating requires a holistic approach to be taken (McCabe 2005; Morris 2018). We believe that initiatives such as the AEM programme which aim to improve the English capabilities of students, educate them on expected academic conduct practices, and discourage contract cheating fit this definition, and our results demonstrate how doing so may assist with this goal.

\section{Conclusion}

This paper has discussed the introduction of an intervention designed to improve the academic writing skills of students, reduce levels of plagiarism, and provide a tool to assist in the detection of contract cheating by capturing a 'fingerprint' of a writing sample. 
The data collected over the course of 12 semesters show a $37.01 \%$ decrease in the rate of detected plagiarism following the introduction of the AEM intervention, and suggest that the introduction of a programme like this could help institutions with reducing plagiarism.

The levels of detected contract cheating cases did decrease following the introduction of the intervention, however, the very small numbers of detected contract cheating cases both pre and post intervention mean that we cannot make a conclusion regarding the use of collecting writing samples as an effective tool to help detect these cases. We have recognised the limitations of this fingerprinting exercise and suggested potential mitigations to these through faculty training.

Despite using a large database of student submissions $(n=12,937)$, the data shows surprisingly low levels $(3.36 \%)$ of detected plagiarism overall, which do not match the high prevalence of plagiarism that has previously been recorded in the literature, however, by analysing detected cases of plagiarism data as opposed to student self-reported data, it is possible that this study may have underestimated plagiarism in the student body. Previous studies have used much smaller samples of student submissions in their analysis, which suggests that different results may be obtained when examining larger sets of data. We therefore recommend that further research should try to use longitudinal university or department wide databases for analysis purposes, as opposed to individual class submissions, as this may give a more accurate representation of the prevalence of plagiarism in an institution.

The issue of academic misconduct is becoming increasingly more visible to the general public. In the United Kingdom, 40 university leaders have written to the Minister of State for Universities, Science, Research and Innovation demanding a ban on companies offering contract cheating services (BBC News 2020), and the Advertising Standards Authority has already banned misleading advertisements from one of these companies (Advertising Standards Agency, 2019). We recognise that the costs required for an intervention strategy such as the AEM may pose a barrier to entry for many institutions, but given the increasing focus on academic integrity, this is not an issue that universities can afford to ignore. We therefore recommend the use of similar initiatives in other institutions as a potential method to educate students about expected academic practice, reduce plagiarism, and believe the potential benefits justify the challenges of introducing such an initiative.

\section{Abbreviations}

AEM: Academic English Masterclass; BUV: British University Vietnam; EAP: English for Academic Purposes; NNES: NonNative English speaker

\section{Acknowledgements}

The authors would like to thank Louise Cotrel-Gibbons for her kind support in offering suggestions for improvement and proof reading of this article.

Availability of data and data materials

Data not available due to confidentiality of student information.

Authors'contributions

All authors contributed to this work. The percentage of contributions is indicated by the order of authorship provided.

The author(s) read and approved the final manuscript.

Funding

The authors received no funding for this work. 


\section{Competing interests}

All authors were employed by the university in question during the time of authorship of the paper.

\section{Author details}

${ }^{1}$ British University Vietnam, BUV Ecopark Campus, Ecopark Township, Hung Yen, Vietnam. ²Duy Tan University, 3 Quang Trung, Danang City, Vietnam.

Received: 23 September 2019 Accepted: 24 March 2020

Published online: 01 May 2020

\section{References}

Abasi A, Graves B (2008) Academic literacy and plagiarism: conversations with international graduate students and disciplinary professors. J Engl Acad Purp 7:221-233. https://doi.org/10.1016/j.jeap.2008.10.010

Advertising Standards Authority (2019) ASA ruling on the Oxbridge research group Itd t/a Oxbridge essays. In: Asa.org.uk. https://www.asa.org.uk/rulings/the-oxbridge-research-group-ltd-a18-458914.html. Accessed 17 Mar 2020

Amigud A, Lancaster T (2019) I will pay someone to do my assignment: an analysis of market demand for contract cheating services on twitter. Assess Eval High Educ. https://doi.org/10.1080/02602938.2019.1670780

Andrews G, Smith A, Henzi D, Demps E (2007) Faculty and student perceptions of academic integrity at US and Canadian dental schools. J Dent Educ 71:1027-1039

Barrett R, Malcolm J (2006) Embedding plagiarism education in the assessment process. Int J Educ Integr 2:38-45

BBC News (2018) Unis demand ban on essay-writing firms. In: bbc.com/news. https://www.bbc.com/news/education-4564 0236. Accessed 21 Mar 2020

Belter R, du Pré A (2009) A strategy to reduce plagiarism in an undergraduate course. Teach Psychol 36:257-261. https://doi. org/10.1080/00986280903173165

Bennett K, Behrendt L, Boothby J (2011) Instructor perceptions of plagiarism. Teach Psychol 38:29-35. https://doi.org/10.1177/ 0098628310390851

Bennett R (2005) Factors associated with student plagiarism in a post-1992 university. Assessment Evaluation Higher Educ 30: 137-162. https://doi.org/10.1080/0260293042000264244

Bradley E (2015) Using computer simulations and games to prevent student plagiarism. J Educ Technol Syst 44:240-252. https://doi.org/10.1177/0047239515617653

Bretag T (2007) The emperor's new clothes: yes, there is a link between English language competence and academic standards. People Place 15:13-21

Bretag T, Harper R, Burton M, Ellis C, Newton P, Rozenberg P, Saddiqui S, van Haeringen K (2019) Contract cheating: a survey of Australian university students. Stud High Educ 44:1837-1856. https://doi.org/10.1080/03075079.2018.1462788

Cai L (2013) Students' perceptions of academic writing: a needs analysis of EAP in China. Language Education in Asia 4:5-22. https://doi.org/10.5746/leia/13/v4/i1/a2/cai

Carroll J (2007) A handbook for deterring plagiarism in higher education. Oxford Centre for Staff Learning and Development, Oxford

Chen T, Ku TNK (2007) EFL students: factors contributing to online plagiarism. Student Plagiarism in an Online World: Problems and Solutions: Problems and Solutions

Chen Y, Van Ullen M (2011) Helping international students succeed academically through research process and plagiarism workshops. Coll Res Libr 72:209-235. https://doi.org/10.5860/crl-117rl

Clare J, Walker S, Hobson J (2017) Can we detect contract cheating using existing assessment data? Applying crime prevention theory to an academic integrity issue. Int J Educ Integrity. https://doi.org/10.1007/s40979-017-0015-4

Clarke R, Lancaster T (2007) Establishing a systematic six-stage process for detecting contract cheating. The Second International Conference on Pervasive Computing and Applications

Coulthard M (2010) Forensic Linguistics: the application of language description in legal contexts. Langage et société 132 (2):15.

Curtis G, Clare J (2017) How prevalent is contract cheating and to what extent are students repeat offenders? J Acad Ethics 15:115-124. https://doi.org/10.1007/s10805-017-9278-x

Curtis G, Gouldthorp B, Thomas E, O'Brien G, Correia H (2013) Online academic-integrity mastery training may improve Students' awareness of, and attitudes toward, plagiarism. Psychology Learning Teaching 12:282-289. https://doi.org/10. 2304/plat.2013.12.3.282

Davis L (2011) Arresting student plagiarism: are we investigators or educators? Bus Commun Q 74:160-163. https://doi.org/ $10.1177 / 1080569911404053$

Dawson, P. Sutherland-Smith, W Ricksen, M. (2019). Can software improve marker accuracy at detecting contract cheating? A pilot study of the Turnitin authorship investigate alpha. Assessment \& Evaluation in Higher Education. Advance online publication DOl: https://doi.org/10.1080/02602938.2019.1662884d

Dawson P, Sutherland-Smith W (2018) Can training improve marker accuracy at detecting contract cheating? A multi-disciplinary pre-post study. Assess Eval High Educ 44:715-725. https://doi.org/10.1080/02602938.2018.1531109

Ba DK, Ba DK, Lam QD, Le DTBA, Nguyen P, Nguyen PL, Nguyen PQ, Pham QL (2016) Student plagiarism in higher education in Vietnam: an empirical study. Higher Educ Res Dev 36:934-946. https:/doi.org/10.1080/07294360.2016.1263829

Ellis C, Zucker I, Randall D (2018) The infernal business of contract cheating: understanding the business processes and models of academic custom writing sites. Int J Educ Integr. https://doi.org/10.1007/s40979-017-0024-3

Fazel I, Kowkabi N (2014) Students' source misuse in language classrooms: sharing experiences. TESL Can J 31:86. https://doi. org/10.18806/tesl.v31i1.1168

Goh E (2015) Exploring underlying motivations behind extreme cases of plagiarism in tourism and hospitality education. J Hospitality Tourism Educ 27:80-84. https://doi.org/10.1080/10963758.2015.1033101

Guo X (2011) Understanding student plagiarism: an empirical study in accounting education. Accounting Education 20:1737. https://doi.org/10.1080/09639284.2010.534577

Harper R, Bretag T, Rundle K (2020) Detecting contract cheating: examining the role of assessment type. Higher Education Research \& Development 1-16. https://doi.org/10.1080/07294360.2020.1724899 
Heckler N, Forde D, Bryan C (2012) Using writing assignment designs to mitigate plagiarism. Teach Sociol 41:94-105. https:// doi.org/10.1177/0092055×12461471

Hoanca B (2019) Combating plagiarism: a three-pronged approach to reducing prevalence in higher education. In: Scholarly ethics and publishing: breakthroughs in research and practice 532-548. IGI Global, Hershey

Jones D (2011) Academic dishonesty: are more students cheating? Bus Commun Q 74:141-150. https://doi.org/10.1177/ 1080569911404059

Jones M, Sheridan L (2014) Back translation: an emerging sophisticated cyber strategy to subvert advances in 'digital age' plagiarism detection and prevention. Assess Eval High Educ 40:712-724. https://doi.org/10.1080/02602938.2014.950553

Kakkonen T, Mozgovoy M (2010) Hermetic and web plagiarism detection Systems for Student Essays_an Evaluation of the state-of-the-art. J Educ Comput Res 42:135-159. https://doi.org/10.2190/ec.42.2.a

Koppel M, Winter Y (2014) Determining if two documents are written by the same author. J Assoc Inf Sci Tech 65:178-187.

Lancaster T, Culwin F (2007) Preserving academic integrity? Fighting against nonoriginality agencies. Br J Educ Technol 38 : 153-157. https://doi.org/10.1111/j.1467-8535.2006.00491.x

Levine J, Pazdernik V (2018) Evaluation of a four-prong anti-plagiarism program and the incidence of plagiarism: a five-year retrospective study. Assess Eval High Educ 43:1094-1105. https://doi.org/10.1080/02602938.2018.1434127

Li Y (2015) Academic staff's perspectives upon student plagiarism: a case study at a university in Hong Kong. Asia Pacific J Educ 35:14-26. https://doi.org/10.1080/02188791.2013.835710

Lines $L$ (2016) Ghostwriters guaranteeing grades? The quality of online ghostwriting services available to tertiary students in Australia. Teach High Educ 21:889-914. https://doi.org/10.1080/13562517.2016.1198759

Malesky L, Baley J, Crow R (2016) Academic dishonesty: assessing the threat of cheating companies to online education. Coll Teach 64:178-183. https://doi.org/10.1080/87567555.2015.1133558

Marshall S, Garry M (2006). NESB and ESB students' attitudes and perceptions of plagiarism. International Journal For Educational Integrity, 2:26-37.

Martin D (2011) Culture and unethical conduct: understanding the impact of individualism and collectivism on actual plagiarism. Manag Learn 43:261-273. https://doi.org/10.1177/1350507611428119

McCabe D (2005) Cheating among college and university students: a north American perspective. Int J Educ Integr 1:1-11

McKeever L (2006) Online plagiarism detection services—saviour or scourge? Assess Eval High Educ 31:155-165. https://doi. org/10.1080/02602930500262460

McLafferty C, Foust K (2004) Electronic plagiarism as a college Instructor's nightmare-prevention and detection. J Educ Bus 79:186-190. https://doi.org/10.3200/joeb.79.3.186-190

Morris E (2018) Academic integrity matters: five considerations for addressing contract cheating. International journal for educational integrity 14. https://doi.org/10.1007/s40979-018-0038-5

Mozgovoy M, Kakkonen T, Cosma G (2010) Automatic student plagiarism detection: future perspectives. J Educ Comput Res 43:511-531. https://doi.org/10.2190/ec.43.4.e

Nation P, Macalister J (2010) Language curriculum design. Routledge, London

Nunan D (1988) Syllabus Design. Oxford University Press, Oxford

O'Donnell K (2011) Linking multimodal communication and feedback loops to reinforce plagiarism awareness. Bus Commun Q 74:216-220. https://doi.org/10.1177/1080569911404404

Park C (2004) Rebels without a clause: towards an institutional framework for dealing with plagiarism by students. J Furth High Educ 28:291-306. https://doi.org/10.1080/0309877042000241760

Pennycook A (1996) Borrowing Others' words: text, ownership, memory, and plagiarism. TESOL Q 30:201. https:/doi.org/10.2307/ 3588141

Perkins M, Gezgin U, Roe J (2018) Understanding the relationship between language ability and plagiarism in nonnative English speaking business students. J Acad Ethics 16:317-328. https://doi.org/10.1007/s10805-018-9311-8

Probett C (2011) Plagiarism prevention. Bus Commun Q 74:170-172. https://doi.org/10.1177/1080569911404054

Rundle K, Curtis G, Clare J (2019) Why students do not engage in contract cheating. Front Psychol. https://doi.org/10.3389/ fpsyg.2019.02229

Scanlon P, Neumann D (2002) Internet plagiarism among college students. J Coll Stud Dev 43:374-385

Scheg A (2012) The impact of Turnitin to the student-teacher relationship. J Interdisciplinary Stud Educ 2:29-38

Soto J, Anand S, McGee E (2004) Plagiarism avoidance. J Coll Sci Teach 33:42

Stetter ME (2013) Teaching students about plagiarism using a web-based module. J Furth High Educ 37:675-693

Stowers R, Hummel J (2011) The use of technology to combat plagiarism in business communication classes. Bus Commun Q 74:164-169. https://doi.org/10.1177/1080569911404406

Tran U, Huynh T, Nguyen H (2017) Academic integrity in higher education: the case of plagiarism of graduation reports by undergraduate seniors in Vietnam. JAcad Ethics 16:61-69. https://doi.org/10.1007/s10805-017-9279-9

Walker C, White M (2014) Police, design, plan and manage: developing a framework for integrating staff roles and institutional policies into a plagiarism prevention strategy. J High Educ Policy Manag 36:674-687. https://doi.org/10.1080/1360080x.2014.957895

Walker J (2010) Measuring plagiarism: researching what students do, not what they say they do. Stud High Educ 35:41-59. https://doi.org/10.1080/03075070902912994

Wallace M, Newton P (2014) Turnaround time and market capacity in contract cheating. Educ Stud 40:233-236. https://doi. org/10.1080/03055698.2014.889597

Warn J (2007) Plagiarism software: no magic bullet!. Higher Education Research \& Development 25 (2):195-208. https://doi. org/10.1080/07294360600610438

\section{Publisher's Note}

Springer Nature remains neutral with regard to jurisdictional claims in published maps and institutional affiliations. 